\title{
Review
}

\section{Diabetes in the young: a paediatric and epidemiological perspective}

\author{
G. Soltész \\ Department of Paediatrics, University of Pécs, Pécs, Hungary
}

\section{Abstract}

The spectrum of diabetes in the young has widened; it now includes monogenic diseases, for example the various forms of permanent and transient neonatal diabetes and MODY as well as the emerging obesityassociated Type 2 diabetes in late childhood, but the main form is still Type 1 diabetes. Age-related major medical, physiological, social and emotional problems make the clinical management of diabetes in children and adolescents a difficult task for the physician and the family. Overall glycaemic control remains moderate or poor despite a treatment schedule, which interferes with several elements of "normal" childhood.

There is an up to tenfold geographical variation in the incidence of childhood Type 1 diabetes within Europe with relatively stable incidence rates in some countries (mainly northern), but dynamic increases in incidence in other countries (mainly central European).

A number of nongenetic (environmental) factors have been associated with the risk of Type 1 diabetes. Among these, perinatal factors, early nutrition, growth and vaccinations, atopic diseases and vitamin $\mathrm{D}$ are discussed in detail. The important interplay between genes, organism and environment is illustrated with new genetic data supporting the importance of environmental pressures in the evolution of this major disease.

Although Type 1 diabetes usually accounts for only a minority of the total impact of diabetes in a population, it is the predominant form of the disease in younger age-groups in most developed countries. It is estimated that on an annual basis almost 100000 children younger than 15 years of age develop Type 1 diabetes worldwide. The autoimmune destruction of the pancreatic beta cells in Type 1 diabetes leads to absolute insulin dependence and a high rate of complications typically occuring at a relatively young age. Therefore, Type 1 diabetes places a particulary heavy burden on the individual, the family and health services. [Diabetologia (2003) 46:447-454]

Keywords Type 1 diabetes, children and adolescents epidemiology, incidence, nongenetic (environmental) risk factors, genes and environment.
Received: 29 January 2002 / Revised: 25 March 2003

Published online: 11 April 2003

CC Springer-Verlag 2003

Corresponding author: G. Soltész, Department of Paediatrics, University of Pécs, 7. József Attila St, 7623 Pécs, Hungary

E-mail: gyula.soltesz@aok.pte.hu

Abbreviations: SDS, Standard deviation score; EURODIAB, Europe and Diabetes.

The 2002 Somogyi Lecture of the European Association for the Study of Diabetes presented on 1 September 2002

\section{The spectrum of diabetes in the young}

Although Type 1 diabetes remains the main form of diabetes in the young, there are a growing number of much less common inherited diabetes syndromes and Type 2 diabetes can also present in early life. Inherited diabetes syndromes, particularly the various forms of MODY have received attention in recent publications $[1,2]$ but other special forms of early diabetes, e. $g$. neonatal diabetes are less known by diabetologists. On the other hand, Type 2 diabetes in children and adoles- 
cents is regarded as an emerging problem; however, there are few reliable reports of its true population prevalence or its prevalence in obese children [3]. Therefore, before turning our attention to Type 1 diabetes, these two conditions presenting at the opposite ends of the paediatric-age spectrum will be briefly discussed as illustrations of the widening spectrum of diabetes in the young.

Neonatal diabetes deserves inclusion because of the new developments with potential importance to our knowledge of pancreatic development and pathology.

Neonatal diabetes is a rare condition $(1 / 400000$ newborns) presenting after birth in two main variants, transient and permanent neonatal diabetes. Patients need insulin therapy to maintain euglycaemia. Several groups, including ours, have shown that neonatal diabetes is not associated with high-risk Type 1 diabetes HLA DQ alleles and islet-specific autoantibodies, and transient and permanent neonatal diabetes are different disease entities $[4,5]$.

In a large cohort of patients, a group has recently shown that there are major differences in birth weight, age at presentation, insulin requirement (with considerable overlap) and genetic background between the two variants [4]. Infants with permanent neonatal diabetes mellitus are less likely to have intrauterine growth retardation (over two thirds of the babies with the transient form have intrauterine growth retardation), are older at diagnosis and usually have higher insulin requirements [4]. The genetic anomalies hitherto described in the permanent form include a deletion in the PDX (IPFI) gene [6] and a mutation of the glucokinase gene [7]. The gene defects identified in transient neonatal diabetes imply an overexpression of an imprinted gene that displays paternal expression. Among these defects, paternal uniparental isodisomy of chromosome 6 (e.g. the inheritance of two chromosome homologs from father only) was first discovered $[4,5,8,9,10,11,12]$. Other patients have had partial duplication of the long arm of the paternal chromosome 6 [4] and methylation defects at 6q24 [4]. Possible candidate genes for transient neonatal diabetes identified in this chromosomal region are the cell cycle control gene $Z A C$ and a gene of unknown function called HYMAI [13, 14]. The eventual identification of the transient neonatal diabetes gene(s) could yield important insights into early beta-cell development, fetal growth and perhaps more common types of diabetes. In up to $30 \%$ of the cases, diabetes relapses later in life.

Towards the other end of the paediatric-age spectrum is the obesity-associated IGT and Type 2 diabetes. The childhood obesity epidemic in the United States has been accompanied by an increase in the prevalence of Type 2 diabetes. In a multiethnic cohort of 167 American obese children and adolescents (using OGTT) IGT was detected in 21 percent of obese adolescents (BMI 35.5 \pm 1 ) and silent Type 2 diabetes was identified in 4 percent of obese adolescents [15]. The data are very scarce for the European population. In a recent survey of 207 obese Hungarian adolescents (BMI 30.9 \pm 4.8 ) the prevalence of IGT was found to be 15 percent and that of silent Type 2 diabetes was 2 percent [16]. Both studies have shown that impaired glucose tolerance, which is thought to be an intermediate stage in the natural history of Type 2 diabetes, is highly prevalent among adolescents with gross obesity. A recent editorial [17] commenting on the obesity epidemic, mordantly observed that the Darwinian evolutionary view of, survival of the fittest 'may have to be replaced by the view of, survival of the fattest'.

\section{A paediatric perspective}

As compared to the Type 1 diabetic patient of the adult physician, there are major physiological, medical, psychological, social and emotional differences. These differences arise from the stages of growth and development of the child (infants and toddlers, preschool years, schoolchildren and adolescents). Each period poses special management problems regarding insulin requirements, monitoring the effects of insulin and the responsibilities of the child and the parents. The problems of the two most difficult periods are briefly summarized in Table 1 and 2 . The transition from paediatric to adult diabetes care can be another traumatic experience if not carefully planned and implemented. In addition to these problems the adverse effects of severe hypoglycaemia on the developing

Table 1. Infants and toddlers with diabetes

\begin{tabular}{lll}
\hline Insulin need & Monitoring & Family \\
\hline - Fast growth rate & - Inability to describe symptoms & - Total dependence on parents \\
- Frequent infections & - Adverse psychological effect of blood & - Parent/child and husband/wife \\
& relationship is affected \\
- Metabolic and fluid imbalance & - Lack of cooperation & \\
- Erratic eating habits & & \\
- Unpredictable physical activity & &
\end{tabular}

Problems with the accurate administration of small doses of insulin 
Table 2. Adolescents with diabetes

\begin{tabular}{|c|c|c|}
\hline Insulin need & Monitoring & Family \\
\hline - Rapid growth rate & - Increased lack of compliance & $\begin{array}{l}\text { - Decreasing influence of parents } \\
\text { ("PARENTECTOMY") }\end{array}$ \\
\hline
\end{tabular}

brain also seem to be more profound. Up to 80 percent of diabetic children with a history of severe hypoglycaemia were found to have permanent electrophysiological abnormalities [18].

The parents of a diabetic child have to face the daily necessity of inflicting pain to their own child and the never-ending daily demands of living with diabetes (eternal vigilance). The following sentence is a poignant quotation from a parent of a young diabetic child: "You get at least one good night's sleep in a month because you forgot to set the alarm for 2:00 am". The mother of an adolescent diabetic girl remembered her child saying "I have been really high today" and she meant blood sugar. The paediatric diabetologist focusing on good metabolic control must be aware that diabetes means not only the loss of pancreatic beta-cell function, but also the loss of a number of elements of normal childhood, among others the loss of the right to be carefree and free of pain.

The metabolic control in 2873 children and adolescents was studied in 1995 and 1998 in 21 centres from Europe, Japan and the United States [19, 20]. From the mean glycated haemoglobin value $(8.7 \%)$ of this large international study it is staggeringly obvious that despite the almost unacceptable psychological, emotional and social price, the level of glycaemic control achievable in children with modern insulin therapy is far from satisfactory.

\section{Descriptive epidemiology of Type 1 diabetes in Europe}

To reliably map the incidence of childhood Type 1 diabetes in Europe, high-quality incidence data are needed which are uniformly collected via a standard protocol from population-based registries. To collect these data the EURODIAB collaborative group was established in 1988 [21, 22]. The network consists of 44 European centres covering about 30 million children and most European nations. The first finding of the group was a large, up to tenfold variation in the incidence of childhood Type 1 diabetes in the European continent [21, 23]. The incidence rates were highest in northern and north-western Europe and lowest in southern and eastern Europe. The incidence in northern Europe is the highest in the world.

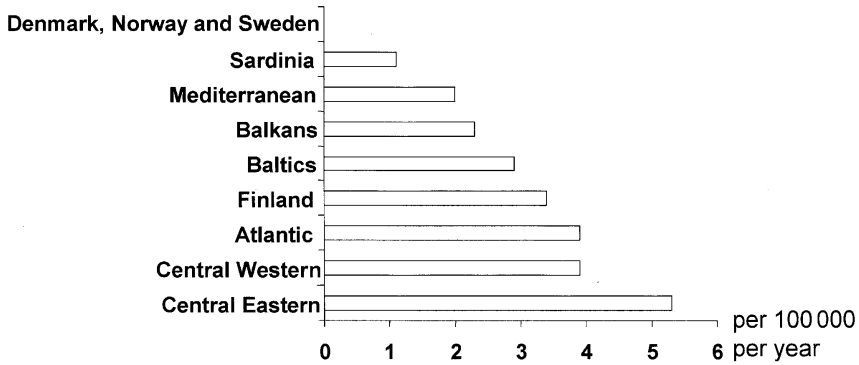

Fig. 1. Annual rate of increase in the incidence of childhood Type 1 diabetes in European regions (1989-1998) [27]

The public health consequences of high incidence of diabetes in regions like Scandinavia are readily appreciated. The possible effects of low incidence such as ignorance by society, delayed diagnosis and higher onset and early mortality are less obvious. Using the EURODIAB database, an inverse correlation was found between the frequency of ketoacidosis at onset and incidence rate. Up to 60 percent of cases had ketoacidosis at diagnosis in low incidence countries [24].

The large geographical variation in incidence could be due to differences in genetic susceptibility or differences in the environment. The increasing incidence over a relatively short period shown in the EURODIAB study [23] and reported in several other publications [25], however, most likely reflect environmental changes. The increase in incidence was observed in all age groups, but it was most pronounced in the youngest age group (0-4 years) [23]. It is also important to emphasise that the increasing incidence was not a uniform trend throughout Europe. The incidence seemed to be stable in some Nordic countries, but dynamic increases were seen in some, mainly CentralEuropean countries (Fig. 1) [26]. One could speculate that these latter countries are still at an earlier stage of the natural evolution of the disease (vide infra).

Non-genetic risk factors of childhood onset Type 1 diabetes (EURODIAB case-control studies)

Apart from the rapid-changes in incidence over time (vide supra), the findings of low concordance rates in monozygotic twins also strongly support the contribu- 
tion of non-genetic risk factors to the aetiology of Type 1 diabetes. The identification of the environmental risk factors would be important because their "elimination" could be an essential part of future preventive measures.

The following discussion will focus on the recent results of the EURODIAB Substudy 2, a large multicenter case-control study that aimed to identify exposures operating early in life that were associated with childhood-onset Type 1 diabetes. The eight participating centres of EURODIAB Substudy 2 represented a large range of Type 1 diabetes incidence and health care policies (e.g. delivery practices and vaccination programs). The study therefore was an opportunity to investigate whether risk factors previously identified in specific populations were also operating in different European countries and to identify exposures that might be too common or too rare in specific populations to detect. Information was collected on perinatal data, early nutrition, growth and development, infectious diseases, atopic diseases and vaccinations.

Among the perinatal risk factors we confirmed previous findings $[27,28,29,30]$ that older maternal age, maternal preeclampsia, neonatal respiratory disease and jaundice were significant risk factors for Type 1 diabetes [31]. Maternal age and jaundice in the newborn were further analysed in this study. It was found that there was a progressive increase in risk in children born to mothers older than 25 years of age [32]. As maternal age at delivery has risen across Europe over the last 20 years, this phenomenon - first observed in the Bart's-Oxford family study [33] - may well have contributed to the rising incidence of childhood diabetes. As far as jaundice in the newborn is concerned, a logistic regression analysis has shown, that jaundice caused by blood-group incompatibility was a strong and independent risk factor (odds ratio 3.06) [34]. The mechanism, by which blood-group incompatibility is associated with the risk of Type 1 diabetes, is not known. One could speculate a direct effect on the beta cells by the naturally occurring $\mathrm{A}$ and $\mathrm{B}$ antibodies, as the $\mathrm{ABO}$ antigens are not restricted to erythrocytes but are also found on the leukocytes.

A further interesting observation was the reduced risk of diabetes associated with low birth weight and short birth length [31]. This finding was confirmed and extended in a recent large Norwegian study, which showed that the incidence rate increased almost linearly with birth weight [34]. As an increase in mean birth weight has been observed in many countries, one could conclude that the secular trend in birth weight could be yet another factor, which contributed to the rise in the incidence of Type 1 diabetes.

If the intrauterine rate of increase in body weight and length is associated with the risk of diabetes in childhood, the question arises, whether the rate of postnatal growth has a similar effect, if any? It has already been suggested several years ago, that the peaking of the incidence of childhood Type 1 diabetes

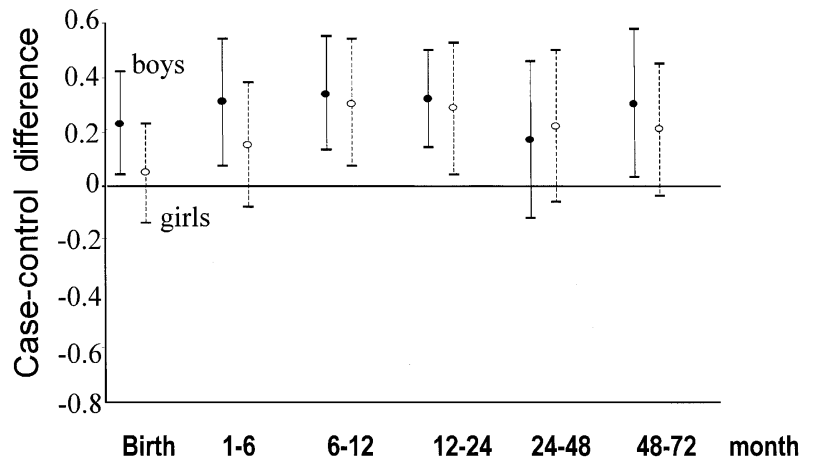

Fig. 2. Case/control subject differences in SDS for growth measurements taken at different ages [42]

around the start of puberty might be due to the high growth rate during puberty causing an increased demand on the insulin-producing beta cells [35, 36]. Subsequently, a large population based study using routinely recorded data showed that a high growth rate many years before disease onset was also a risk factor [37], a finding, which was later corroborated by studies showing greater weight gains during the first year of life $[38,39]$ and increased BMI throughout childhood [40]. In our multicentre study, growth data were obtained from routine clinical and outpatient records and the differences between patients and control subjects were expressed as standard deviation scores (SDS) [41]. Significant differences in height SDS were evident even at birth and these differences increased in magnitude to a maximum between ages 1 and 2 years. Differences showed a similar pattern for boys and girls, although they tended to be larger for boys at most ages (Fig. 2). In other words, prediabetic children were taller than their peers for up to 5 years of age. Even higher differences were seen for weight (maximum difference in SDS 0.41) suggesting that nutritional factors might have been responsible for the faster gain in weight in prediabetic children. The association between growth and risk of childhood diabetes is also consistent with the Accelerator Hypothesis [42] and with the ecological association between gross national product and diabetes incidence in different countries [43] since childhood growth is known to reflect population wealth [44].

The prevention of some of the most devastating infectious diseases of childhood by vaccinations was probably one of the greatest benefits that medicine has provided. However, as the seriousness of the target diseases is forgotten, the possible adverse effects of vaccines by way of their effect on the immune system become the main concern for the public. As far as Type 1 diabetes is concerned, it has been suggested that vaccinations could increase the risk and risk could be altered by changes in the timing of vaccinations [45]. A possible protective effect was suggested for BCG vaccination [46]. Our study, one of the largest 
case-control studies yet conducted to address this issue, found no evidence to support vaccinations (against rubella, morbilli, varicella, pertussis, poliomyelitis, diphtheria, tetanus, parotitis and haemophilus influenza B) modulating the risk of childhood Type 1 diabetes [47]. Furthermore, no support was found for the hypothesis that early BCG vaccination was protective [47, 48]. A recent American case-control study confirmed this observation for the so called "traditional" vaccinations and provided data on newer vaccines including hepatitis $B$, acellular pertussis and varicella vaccines [49].

The balance between $\mathrm{Th}_{1}$ and $\mathrm{Th}_{2}$ lymphocytes and cytokines seems to be of importance in the expression of autoimmune diseases including Type 1 diabetes [50]. Type 1 diabetes, autoimmune thyroid diseases and rheumatoid arthritis are considered as $\mathrm{Th}_{1}$-mediated organ-specific autoimmune diseases and atopy as a $\mathrm{Th}_{2}$ - mediated disease [51, 52, 53]. Although this could be an oversimplification [54], it was hypothesised that to a certain degree, $\mathrm{Th}_{1}$ and $\mathrm{Th}_{2}$ diseases could be mutually exclusive. Consequently, our hypothesis was that the prevalence of atopic diseases asthma, allergic rhinoconjunctivitis and eczema is decreased in children with Type 1 diabetes. In the EURODIAB cohort of children we have found that the presence of all three atopic diseases conferred an up to $30 \%$ decrease in the risk of Type 1 diabetes [55]. Subsequently, this finding was replicated in a Finnish and English study showing an even larger degree of protection against Type 1 diabetes by the atopic disease, asthma [56, 57]. Recently, a decreased prevalence of atopic conditions was found in rheumatoid arthritis, another $\mathrm{Th}_{1}$-mediated organ-specific autoimmune disease [58].

It has been shown, that treatment with the active form of vitamin D prevented the development of insulitis in the non-obese diabetic mouse, a model for human Type 1 diabetes and an analogue of 1 alpha; 25 hydroxy vitamin $\mathrm{D}$ at non-hypercalcaemic doses arrested $\mathrm{Th}_{1}$ cell infiltration and progression of insulitis $[59,60]$. Epidemiological studies describing a northsouth gradient in incidence rate and an inverse correlation between incidence and mean monthly sunshine hours were also hinting at a possible protective effect of vitamin D [61, 62]. In the EURODIAB case-control-study early vitamin D supplementation was associated with a decreased risk of Type 1 diabetes (odds ratio 0.67). Adjustment for possible confounders, such as low birth weight, short duration of breast-feeding and old maternal age in logistic regression analysis did not affect the protective effect of vitamin D [63]. Subsequently, a birth cohort study from Finland showed a strong protective effect of vitamin $\mathrm{D}$ given during the first year [64] with a clear dose-response effect (the higher the dose of vitamin $\mathrm{D}$, the more effective the protection). It has also been shown in Norway, that the risk of diabetes in the offspring of moth-
Table 3. Non-genetic (environmental) risk factors in childhood onset Type 1 diabetes

Factors associated

with increased risk

with reduced risk

Viral infections during pregnancy

Older maternal age

Blood group incompatibility

Cow's milk proteins

$\mathrm{N}$-nitroso compounds

Increased growth rate

Stressful life events
Low birth weight Short birth length Breast-feeding Early vitamin D supplementation Pre-school day-care Atopic diseases

ers who consumed cod liver oil (containing vitamin D and n-3 fatty acids) was lower [65]. It can be assumed that vitamin $\mathrm{D}$ acts as an immunomodulating agent and might inhibit the autoimmune process targeted against the beta cells of the pancreas. Further work is needed, however, to delineate the potential role of vitamin $\mathrm{D}$ in the pathogenesis of Type 1 diabetes including prospective studies in which biomarkers of vitamin $\mathrm{D}$ are measured at various times before the diagnosis of diabetes [66]. Vitamin D exerts its genomic action via the nuclear vitamin $\mathrm{D}$ receptor (VDR). VDR is expressed in many cell types, including pancreatic beta cells, and its gene shows extensive polymorphism. Therefore it can be hypothesized that vitamin $\mathrm{D}$ receptor allele combinations could influence genetic susceptibility to Type 1 diabetes $[67,68]$.

This partial overview of some of the recently recognized nongenetic (environmental) factors associated with the risk of Type 1 diabetes (the main putative risk factors are summarised in Table $3[69,27]$ ) should not give the false impression that the pursuit for these risk factors is any more important for the better understanding of the aetiology of the disease than the identification of diabetes susceptibility genes. It is generally accepted that Type 1 diabetes is caused by an interaction of genetic and environmental factors. The emphasis should probably be on the interaction in the broadest sense of the world. To quote Richard Lewontin, the brilliant evolutionary biologist, "Taken together, the relations of genes, organisms and environments are reciprocal relations in which all three elements are both causes and effects" [70].

Thinking along these "evolutionary" lines, it will perhaps be appropriate to conclude this overview with the brief discussion of a recent study which was aimed to test the possible effect of changing environment on distribution of HLA genotypes associated with disease susceptibility and protection. One of the best-documented records of childhood diabetes incidence is the Finnish registry. The incidence in Finland has nearly tripled over the last 40 years [71]. The group of researchers in Turku compared the distribution of geno- 
types conferring disease susceptibility and protection in cases diagnosed before 1965 and after 1990 [72]. The frequency of the high-risk genotype DQ2/DQ8 was much lower and the combined frequencies of protective genotypes were much higher in patients diagnosed more recently, as compared to 40 years ago. These changes were interpreted as a result of increasing environmental pressure. Diabetes at the turn of the millennium seems to develop in Finland in genetically "less susceptible" people and also in subjects with "protective" HLA genotypes. This observation is consistent with epidemiological and genetic data from Hungary. In Hungary with much lower incidence of childhood Type 1 diabetes [73], high-risk HLA genotypes in children diagnosed between 1980 and 1996 were more prevalent than in Finland [74], suggesting that Hungary could still be at an earlier stage of the natural evolution of Type 1 diabetes.

Sources. This review is based on the relevant literature published in the English language during the period 1990-2002, and seminal prior contributions. The sources available for the author were integrated with sources identified through PubMed searches for "diabetes in childhood", "epidemiology of childhood diabetes", "environmental risk factors for Type 1 diabetes".

Acknowledgements. The author gratefully acknowledges the substantial contribution of his mentors, collaborators (in his department, in the Hungarian Childhood Diabetes Epidemiology group and in the EURODIAB network), clinical colleagues, residents, students and patients to the work and ideas described in this review. Ms. J. Takács provided invaluable support in the preparation of the manuscript.

\section{References}

1. Pruhova S, Ek J, Lebl J et al. (2003) Genetic epidemiology of MODY in the Czech republic: new mutations in the MODY genes HNF-4 $\alpha$, GCK and HNF-1 $\alpha$. Diabetologia 46:291-295

2. Lambert AP, Ellard S, Allen LIS et al. (2003) Identifying hepatic nuclear factor $1 \alpha$ mutations in children and young adults with a clinical diagnosis of type 1 diabetes. Diabetes Care 26:333-337

3. American Diabetes Association (2000) Type 2 diabetes in children and adolescents. Diabetes Care 23:381-389

4. Metz C, Cavé H, Bertrand A, Deffert C et al. (2002) Neonatal diabetes mellitus: Chromosomal analysis in transient and permanent cases. J Pediatr 141:483-489

5. Hermann R, Laine A-P, Johansson C et al. (2000) Transient but not permanent neonatal diabetes mellitus is associated with paternal uniparental isodisomy of chromosome 6 . Pediatrics 105:49-52

6. Stoffers DA, Zinkin NT, Stanojevic V, Clarke WL, Habener JF (1997) Pancreatic agenesis attributable to a single nucleotide deletion in the human IPF1 gene coding sequence. Nat Genet 15:106-110

7. Njolstad PR, Sovik O, Cuesta-Munoz A et al. (2001) Neonatal diabetes mellitus due to complete glucokinase deficiency. N Engl J Med 344:1588-1592
8. Temple IK, James RS, Crolla JA et al (1995) An imprinted gene(s) for diabetes? Nat Genet 9:110-112

9. Temple IK, Gardner RJ, Mackay DJG, Barber JCK, Robinson DO, Shield JPH (2000) Transient neonatal diabetes. Widening the understanding of the etiopathogenesis of diabetes. Diabetes 49:1359-1366

10. Whiteford ML, Narendra A, White MP et al. (1997) Paternal uniparental disomy for chromosome 6 causes transient neonatal diabetes. J Med Genet 34:167-168

11. Christian SL, Rich BH, Loebl C et al. (1999) Significance of genetic testing for paternal uniparental disomy of chromosome 6 in neonatal diabetes mellitus. J Pediatr 134:42-46

12. Cave H, Polak M, Drunat S, Denamur E, Czernichow P (2000) Refinement of the 6q chromosomal region implicated in transient neonatal diabetes. Diabetes 49:108-113

13. Kamiya M, Judson H, Okazaki Y (2000) The cell cycle control gene ZAC/PLAGL1 is imprinted: a strong candidate gene for transient neonatal diabetes. Hum Mol Genet 9:453-460

14. Arima T, Drewell RA, Arney KL et al. (2001) A conserved imprinting control region at the HYMAI/ZAC domain is implicated in transient neonatal diabetes mellitus. Hum Mol Genet 10:1475-1483

15. Sinha R, Fisch G, Teague B et al. (2002) Prevalence of impaired glucose tolerance among children and adolescents with marked obesity. N Engl J Med 346:802-810

16. Erhardt É, Molnár D, Soltész G (2002) Impaired glucose tolerance and type 2 diabetes in obese Hungarian children. J Pediatr Endocrinol Metab 15 (Suppl 4):1077 (Abstract)

17. Anonymous (2002) Getting a handle on obesity. Lancet 359:1955

18. Soltész G, Acsádi G (1989) Association between diabetes, severe hypoglycaemia, and electroencephalographic abnormalities. Arch Dis Childh 64:992-996

19. Mortensen HB, Hougaard P (1997) Comparison of metabolic control in a cross-sectional study of 2,873 children and adolescents with IDDM from 18 countries. The Hvidore Study Group on Childhood Diabetes. Diabetes Care 20:714-720

20. Holl RW, Swift PGF, Mortensen HB et al. (2003) Insulin injection regimens and metabolic control in an international survey of adolescents with type 1 diabetes over 3 years: results from the Hvidore study group. Eur J Pediatr 162:22-29

21. Green A, Gale EAM, Patterson CC, for the EURODIAB ACE Study Group (1992) Incidence of childhood-onset insulin-dependent diabetes mellitus: the EURODIAB ACE study. Lancet 339:905-909

22. Green A (2001) The EURODIAB studies on childhood diabetes 1988-1999. Diabetologia 44 (Suppl 3):B1-B2

23. EURODIAB ACE Study Group (2000) Variation and trends in incidence of childhood diabetes in Europe. Lancet 355:873-876

24. Lévy-Marchal C, Patterson CC, Green A on behalf of the EURODIAB ACE Study Group (2001) Geographical variation of presentation at diagnosis of type 1 diabetes in children: the EURODIAB Study. Diabetologia 44 (Suppl 3):B75-B80

25. Gale EAM (2002) Perspectives in diabetes. The rise of childhood type 1 diabetes in the 20th century. Diabetes 51:3353-3361

26. Green A, Patterson CC on behalf of the EURODIAB TIGER Study Group (2001) Trends in the incidence of childhood-onset diabetes in Europe 1989-1998. Diabetologia 44 (Suppl 3):B3-B8

27. Åkerblom HK, Vaarala O, Hyöty H, Ilonen J, Knip M (2002) Environmental factors in the etiology of type 1 diabetes. Am J Med Genet 115:18-29 
28. Dahlquist G, Källén B (1992) Maternal-child blood group incompatibility and other perinatal events increase the risk for early onset type 1 (insulin-dependent) diabetes mellitus. Diabetologia 35:671-675

29. Wagener DK, LaPorte RE, Orchard TJ, Cavender D, Kuller LH, Drash AL (1983) The Pittsburgh Diabetes Mellitus Study 3: an increased prevalence with older maternal age. Diabetologia 25:82-85

30. Patterson CC, Waugh NR, Carson DJ, Cole SK, Hadden DR (1994) A case-control investigation of perinatal risk factors for childhood IDDM in Northern Ireland and Scotland. Diabetes Care 17:376-381

31. Patterson CC, Dahlquist G, Soltész G on behalf of the EURODIAB Substudy 2 Study Group (1999) Perinatal risk factors for childhood type 1 diabetes in Europe. Diabetes Care 22:1698-1702

32. Patterson CC, Dahlquist G, Soltész G on behalf of the EURODIAB Substudy 2 Study Group (2001) Maternal age and risk of type 1 diabetes in children. BMJ 322:14891491

33. Bingley PJ, Douek IF, Rogers CA, Gale EAM on behalf of the BOX (Bart's-Oxford) Study Group (2000) Influence of maternal age at delivery and birth order on risk of type 1 diabetes in childhood: prospective population based family study. BMJ 321:420-424

34. Stene LC, Magnus P, Lie RT, Søvik O, Joner G and The Norwegian Childhood diabetes Study Group (2001) Birth weight and childhood onset type 1 diabetes: population based cohort study. BMJ 322:889-892

35. La Porte RE, Fishbein HA, Drash AL et al. (1981) The incidence of insulin-dependent diabetes mellitus (IDDM) in Allegheny County, Pennsylvania (1965-1976). Diabetes 30:279-284

36. Dahlquist G, Gustavsson KH, Holmgren G et al. (1982) The incidence of diabetes mellitus in Swedish children 0-14 years of age. Acta Paediatr Scand 71:7-14

37. Blom L, Persson LA, Dahlquist G (1992) A high linear growth is associated with an increased risk of childhood diabetes mellitus. Diabetologia 35:528-533

38. Johansson C, Samuelsson U, Ludvigsson J (1994) A high weight gain early in life is associated with an increased risk of type 1 (insulin-dependent) diabetes mellitus. Diabetologia 37:91-94

39. Hypponen E, Kenward MG, Virtanen SM et al. (1999) Infant feeding, early weight gain, and risk of type 1 diabetes. Childhood Diabetes in Finland (DiMe) Study Group. Diabetes Care 22:1961-1965

40. Hypponen E, Virtanen SM, Kenward MG, Knip M, Åkerblom H (2000) Obesity, increased linear growth, and risk of type 1 diabetes in children. Diabetes Care 23:1755-1760

41. The EURODIAB Substudy 2 Study Group (2002) Rapid early growth is associated with increased risk of childhood type 1 diabetes in various European populations. Diabetes Care 25:1755-1760

42. Wilkin TJ (2001) The accelerator hypothesis: weight gain as the missing link between type 1 and type 2 diabetes. Diabetologia 44:914-922

43. Patterson CC, Dahlquist G, Soltész G, Green A, on behalf of the EURODIAB ACE Study Group (2001) Is childhoodonset type 1 diabetes a wealth-related disease? An ecological analysis of European incidence rates. Diabetologia 44 (Suppl. 3):B9-B16

44. Tanner JM (1978) Foetus into man: physical growth from conception to maturity. Open Books, London, pp 150-153

45. Classen DC, Classen JB (1997) The timing of pediatric immunization and the risk of insulin-dependent diabetes mellitus. Infect Dis Clin Pract 6:449-454
46. Parent ME, Siemiatycki J, Menzies R, Fritschi L, Colle E (1997) Bacille Calmette-Guerin vaccination and incidence of IDDM in Montreal, Canada. Diabetes Care 20:767-772

47. The EURODIAB Substudy 2 Study Group (2000) Infections and vaccinations as risk factors for childhood Type 1 (insulin-dependent) diabetes mellitus: a multicentre casecontrol investigation. Diabetologia 43:47-53

48. Patterson CC, Dahlquist G, Soltész G on behalf of the EURODIAB Substudy 2 Study Group (2000) Vaccinations as risk factors for Type 1 diabetes mellitus. Diabetologia 43:684

49. DeStefano F, Mullooly JP, Okoro CA et al. (2001) Childhood vaccinations, vaccination timing, and risk of type 1 diabetes mellitus. Pediatrics 108:1<XBody Text $>5$

50. Rabinovitch A (1994) Immunoregulatory and cytokine imbalances in the pathogenesis of IDDM: therapeutic intervention by immunostimulation? Diabetes 43:613-621

51. Romagnani S (1992) Human TH1 and TH2 subsets: regulation of differentiation and role in protection and immunpathology. Int Arch Allergy Immunol 98:279-285

52. Simon AK, Seipelt E, Sieper J (1994) Divergent T-cell cytokine patterns in inflammatory arthritis. Proc Natl Acad Sci USA 91:8562-8566

53. Del Prete G (1992) Human Th1 and Th2 lymphocytes: their role in the pathophysiology of atopy. Allergy 47:450455

54. Prahalad S (2000) Atopy, autoimmunity, and the TH1/TH2 balance. J Pediatr 137:446-449

55. The EURODIAB Substudy 2 Study Group (2000) Decreased prevalence of atopic diseases in children with diabetes. J Pediatr 137:470-474

56. Mattila PS, Tarkkanen J, Saxen H et al. (2002) Predisposition to atopic symptoms to inhaled antigens may protect from childhood type 1 diabetes. Diabetes Care 25:865-868

57. Kouek IF, Leech NJ, Gillmor HA, Bingley PJ, Gale EAM (1999) Children with type-1 diabetes and their unaffected siblings have fewer symptoms of asthma. Lancet 353:1850

58. Allanore Y, Hilliquin P, Coste J, Renoux M, Menkès CJ (1998) Decreased prevalence of atopy in rheumatoid arthritis. Lancet 351:497

59. Mathieu C, Laureys J, Sobis H, Vandeputte M, Waer M, Bouillon R (1992) 1,25-dihydroxyvitamin D3 prevents insulitis in NOD mice. Diabetes 41:1491-1495

60. Gregori S, Giarratana N, Smiroldo S, Uskokovic M, Adorini L (2002) A $1 \alpha, 25$-dihydroxyvitamin $\mathrm{D}_{3}$ analog enhances regulatory t-cells and arrests autoimmune diabetes in NOD mice. Diabetes 51:1367-1374

61. Diabetes Epidemiology Research International Group (1988) Geographic patterns of childhood insulin-dependent diabetes mellitus. Diabetes 37:1113-1119

62. Dahlquist G, Mustonen L (1994) Childhood onset diabetestime trends and climatological factors. Int $\mathrm{J}$ Epidemiol 23:1239-1241

63. The EURODIAB Substudy 2 Study Group (1999) Vitamin $\mathrm{D}$ supplement in early childhood and risk for type 1 (insulin-dependent) diabetes mellitus. Diabetologia 42:51-54

64. Hyppönen E, Läärä E, Reunanen A, Järvelin M-R, Virtanen SM (2001) Intake of vitamin D and risk of type 1 diabetes: a birth-cohort study. Lancet 358:1500-1503

65. Stene LC, Ulriksen J, Magnus P, Joner G (2000) Use of cod liver oil during pregnancy associated with lower risk of Type 1 diabetes in the offspring. Diabetologia 43:10931098

66. Norris JM (2001) Can the sunshine vitamin shed light on type 1 diabetes? Lancet 358:1476-1478

67. McDermott MF, Ramachandran A, Ogunkolade BW et al (1997) Allelic variation in the vitamin D receptor influenc- 
es susceptibility to IDDM in Indian Asians. Diabetologia 40:971-975

68. Pani MA, Knapp M, Donner H et al (2000) Vitamin D receptor allele combinations influence genetic susceptibility to type 1 diabetes in Germans. Diabetes 49:504-507

69. Dahlquist G (1998) The aetiology of type 1 diabetes: an epidemiological perspective. Acta Paediatr Suppl 425:5-10

70. Lewontin R (2000) The Triple helix. Gene, organism and environment. Harvard University Press, Cambridge, p 100

71. Karvonen M, Viik-Kajander M, Moltchanova E, Libman I, LaPort R, Tuomilehto J (2000) Incidence of childhood type 1 diabetes worldwide: Diabetes Mondiale (DiaMond) Project Group. Diabetes Care 23:1516-1526
72. Hermann R, Knip M, Veijola R et al. (2003) Temporal changes in the frequencies of HLA genotypes in patients with type 1 diabetes - indication of an increased environmental pressure? Diabetologia 46:420-425, DOI 10.1007/ s00125.003.1045.4

73. Gyürüs É, Green A, Patterson CC, Soltész G and the Hungarian Childhood Diabetes Epidemiology Study Group (2002) Dynamic changes in the trends in incidence of type 1 diabetes in children in Hungary (1978-98). Pediatr Diabetes 3:194-199

74. Hermann R, Mijovic CH, Rayner M et al. (2001) HLA Alleles and IDDM in children in Hungary: a comparison with Finland. Human Immunol 62:391-398 